\title{
RESEARCH ON ANTI-OVERTURNING PERFORMANCE OF MULTI-SPAN CURVED GIRDER BRIDGE WITH SMALL RADIUS
}

\section{Luo Xu}

\author{
School of Mechanics and Architectural Engineering, Jinan University, Guangzhou, Guangdong Province \\ *Corresponding author Email: tluoxu@jnu.edu.cn
}

This is an open access article distributed under the Creative Commons Attribution License, which permits unrestricted use, distribution, and reproduction in any medium, provided the original work is properly cited.

This is an open access article distributed under the Creative Commons Attribution License, which permits unrestricted use, distribution, and reproduction in any medium, provided the original work is properly cited.

\section{ARTICLE DETAILS}

Article History:

Received 10 December 2017

Accepted 08 January 2018

Available online 19 February 2018

\section{ABSTRACT}

Since the severe situation of small radius curved girder overturning accidents in recent years in China, the research of anti-overturning performance with these bridges are becoming more and more important. In this paper, one small radius multi-span curved girder will be studied in the following procedure. Firstly, the requirements and application conditions of anti-overturning analysis methods at present will be summarized. Secondly, the finite element numerical model of the curved bridge will be built and some calculation and research on its anti-overturning performance will be carried out. Furthermore, the valuable conclusion will be drawn too, which can provide powerful practice and theory reference for the application and research of similar structure.

\section{KEYWORDS}

small radius curved girder, anti-overturning performance, structural finite element analysis

\section{INTRODUCTION}

With the rapid development of urban construction and transportation in China, a variety of complex intersection networks are gradually emerging, in which the small radius curved girder beams with single column pier are widely applied because of lacking city land. The lateral resistance to overturning and stability of these structures are poor especially with the eccentric live load, and there are great security risks. In recent years, there have been many accidents of lateral overturning of bridges in china, such as the overturning event of Baotou National Road East viaduct in 2007, the bridge collapse accident at $\mathrm{C}$ ramp of Heyuan South Interchange in Guangdong Jiangxi Expressway in 2015, etc. These accidents lead to casualties and a great deal of economic losses and cause adverse social impacts. The lateral overturning resistance of curved bridges is a serious situation and needs to be solved urgently.

The calculation of the overturning resistance of the superstructure of the box girder has not been stipulated in current bridge design code in China [1]. In order to improve the design of bridge structures and ensure the safety of the curve girders, relevant formulas have been put forward to calculate the stability factor of overturning structures [2]. In addition, the Guangdong Provincial Department of transportation has commissioned the well-known design institute in the industry to compile the detailed rules and supplementary opinions on the calculation and checking of lateral overturning safety of curved beams $[3,4]$.

Focus on the problem mentioned above, the research of the anti overturning stability will be carried out in this paper, the finite element analysis mode of a multi span small radius curved girder bridge will be built base on previous theories and methods, and the various critical transverse overturning mode will be considered too.

\section{ENGINEERING BACKGROUND}

The research object structure in this paper is one multi-span continuous curved box girder in the plane curve with radius of $67 \mathrm{~m}$, its span combination is $11 \times 20 \mathrm{~m}$, the upper structure is reinforced concrete continuous box girder, except for abutment on both sides in which double support is set, the other piers are single column structure, all the foundation in this bridge are bored pile foundation, the construction procedure of the curve girder is cast-in-situ method with full framing support.

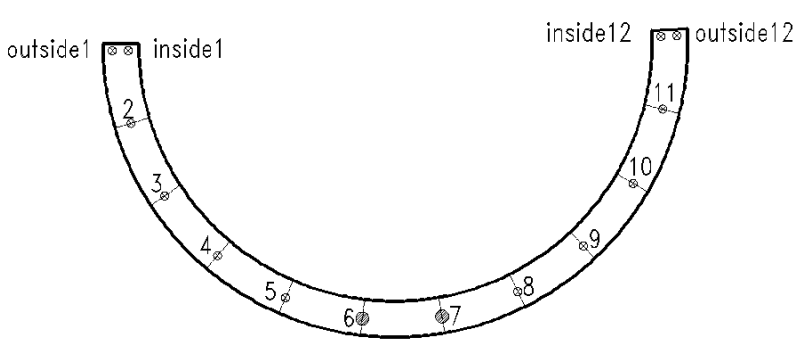

Figure 1: Sketch map of support arrangement

The design load standard of this bridge is Car-20; Designed driving speed is $25 \mathrm{~km} / \mathrm{h}$; The width of the bridge is $9.9 \mathrm{~m}$; The height of the bridge is $1.3 \mathrm{~m}$; The box girder is made of C40 concrete; The bridge deck is made of $8 \mathrm{~cm}$ thick modified asphalt concrete; The box girders are equipped with double supports at the two abutment, all the piles are with support except for 6\# and 7\# piers which are consolidated with piers, the setting and numbering of the support are shown in figure 1.

\section{ESTABLISHMENT OF FINITE ELEMENT MODEL OF CURVED} CONTINOUS GIRDER

\subsection{Calculation Parameter}

a. Loading degree of bridge deck pavement is $16.7 \mathrm{kN} / \mathrm{m}$;

b. The load concentration of bridge anti-collision column is $11.5 \mathrm{kN} / \mathrm{m}$;

c. The weight of the structure is automatically considered by the program by setting the bulk density $(26 \mathrm{kN} / \mathrm{m} 3)$ of the concrete box girder;

d. The values of shrinkage and creep parameters are taken according to the current design codes, the concrete age at the beginning of the contraction takes 3 days, the average annual relative humidity was $70 \%$, and the time of creep and shrinkage was 3650 days.

\subsection{Establishment of Finite Element Model}

The bridge professional analysis program Midas Civil 2015 is used to the finite element analysis of bridge structure. According to the design 
drawings of the bridge, the $3 \mathrm{D}$ elementary beam element is adopted to simulate the curved continuous box girder and its consolidation pier, the boundary conditions of the structure is set accordingly without considering with the pile-soil interaction, it is assumed that the bottom of a consolidated pier is a solid end constraint, the boundary conditions of other supports are set according to drawings. The whole bridge is divided into 300 nodes and 285 units. The finite element model of the bridge is shown as the figure 2 .

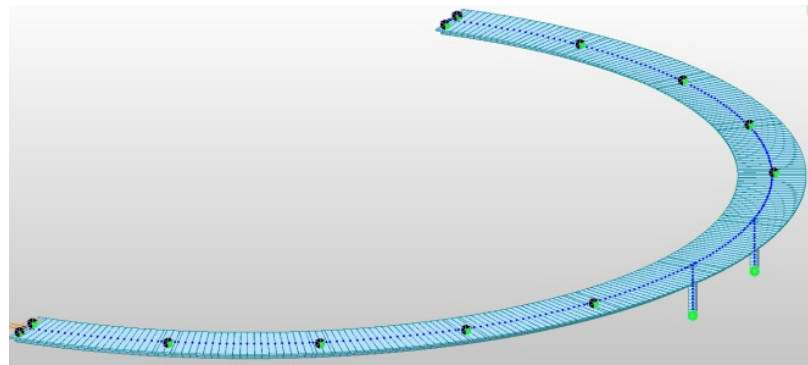

Figure 2: The finite element model of continuous curved box girder with multi span

\section{OVERVIEW OF ANTIOVERTURNING CALCULATION OF CURVED CONTINUOUS BOX GIRDER}

Since There are two piers whose boundary conditions are pier beam consolidation, so long as its strength can meet with the stability requirement of pier bearing capacity in overturning loads without bearing void, the problem of overturning the structure isn't exist in fact. But according to the related literature spirit, the anti overturning performance of the structure of single column must be checked [4].

The bridge deck width is $9.1 \mathrm{~m}$, which is with typical two lanes. According to horizontal layout of vehicles, when the two lanes are both biased outside the curve, the anti-overturning performance of the structure is in the worst condition. The most unfavorable car movement load is set up on the finite element analysis model of the curved continuous box girder with the above analysis.

The correction factor of moving load is $1.035=1.2 \times 1.15 \times 0.75$. Among them, according to the requirements of "highway engineering technical standards" (JTGB01-2014), when a bridge is arranged only to one lane, the load coefficient of the transverse lane is 1.2 [5]. According to the past engineering experience, when the single beam model is used to simulate the continuous box girder, the coefficient of partial load is usually 1.15 [6].

The impact force of automobile load is calculated according to the current code. According to the situation of the bridge, the fundamental frequency of the structure is calculated according to the continuous beam formula of the "general code for the design of highway bridge and culvert" [7]. The fundamental frequency result of the structure is $4.6 \mathrm{~Hz}$ with the formula mentioned above. By analyzing the moving load control options in the Midas Civil 2015 car, the coefficients are automatically taken into account by the program.

\section{CHECKING CALCULATION OF NEGATIVE BEARING REACTION FORCE (THE SUPPORT VOID) OF CURVED GIRDER BRIDGE}

The checking calculation of the bearing separation is actually to check whether the bridge has an uplift force (negative bearing reaction force) under the overturning load or not. In order to reflect the problem conveniently, the calculation results of support counterforce are given in three different load conditions as following:

(1) The standard value load combination $(1.0 \times$ dead load $+1.0 \times$ car live load);

(2) The basic load combination $(1.2 \times$ dead load $+1.4 \times$ car live load);

(3) The basic load combination with considering of overturning $(1.2 \times$ dead load $+3.4 \times$ car live load).

On the basis of the above model, the support reaction force of the bridge under various load cases is calculated by Midas Civil 2015, as shown in Table 1-5. Furthermore, in order to verify that the single lane bias load is more disadvantageous than the dual lane biased load, the reaction force under the two lanes is also listed.

When the middle piers are single column piers and there are double supports on the two abutments or piers at both ends, the counterforce of the outside support of the abutment and the pier at both ends is generally greater than that of the inner support. But since the $30 \mathrm{~cm}$ eccentricity is set outside the single column pier in the middle of the bridge, the counterforce of the outer support is smaller than that of the inner one.

Table 1: The Calculation Results of Support Reaction Under Dead Load (Kn)

\begin{tabular}{|c|c|c|c|}
\hline Support & Reaction Force & Support & Reaction Force \\
\hline outside1 & 573 & 7 & 3421 \\
\hline inside1 & 974 & 8 & 3120 \\
\hline 2 & 2980 & 9 & 3084 \\
\hline 3 & 3407 & 10 & 3419 \\
\hline 4 & 3048 & 11 & 2894 \\
\hline 5 & 3135 & outside12 & 666 \\
\hline 6 & 3419 & inside12 & 931 \\
\hline
\end{tabular}

Note: the support reaction force of consolidated pier of 6 and 7 are both on the bottom of the pier, so do the following tables.

Table 2: The Calculation Results of Support Reaction Under Standard Value Combination $(\mathrm{Kn})$

\begin{tabular}{|c|c|c|}
\hline Support & Two Lanes Bias Loading & Single Lane Bias Loading \\
\hline outside1 & 2110 & 1988 \\
\hline inside1 & 1405 & 974 \\
\hline 2 & 4835 & 4147 \\
\hline 3 & 5204 & 4514 \\
\hline 4 & 4873 & 4184 \\
\hline 5 & 4951 & 4261 \\
\hline 6 & 5194 & 4496 \\
\hline 7 & 5197 & 4498 \\
\hline 8 & 4937 & 4248 \\
\hline 9 & 4910 & 4221 \\
\hline 10 & 5217 & 4526 \\
\hline 11 & 4747 & 4061 \\
\hline outside12 & 2199 & 2077 \\
\hline inside12 & 1362 & 931 \\
\hline
\end{tabular}

According to the related design code, in the design of bridge bearings, the standard combination is generally used as the basis for the selection of bearings. Based on the data in Table 2, there are no negative reaction force with all the bearings under the standard combination load case, and the reaction force two lanes under partial load are bigger than that of single lane, so we can draw the following conclusions that the two-lane vehicle loads on the structure will helps to improve its anti-overturning performance instead.

Table 3: The Calculation Results of Support Reaction under Basic Combination (KN)

\begin{tabular}{|c|c|c|}
\hline Support & $\begin{array}{c}\text { Two Lanes Bias } \\
\text { Loading }\end{array}$ & $\begin{array}{c}\text { Single Lane Bias } \\
\text { Loading }\end{array}$ \\
\hline outside1 & 2793 & 2623 \\
\hline inside1 & 1783 & $\mathbf{- 1 1 7 9}$ \\
\hline 2 & 6255 & 5292 \\
\hline 3 & 6545 & 5579 \\
\hline 4 & 6226 & 5262 \\
\hline 5 & 6305 & 5340 \\
\hline 6 & 6587 & 5609 \\
\hline 7 & 6589 & 5612 \\
\hline 8 & 6291 & 5327 \\
\hline 9 & 6266 & 5300 \\
\hline 10 & 6556 & 5589 \\
\hline 11 & 6165 & 5204 \\
\hline outside12 & 2883 & 2713 \\
\hline inside12 & 1739 & $\mathbf{- 1 1 3 5}$ \\
\hline
\end{tabular}

Table 3 shows the results of reaction forces under the basic combination load case, from which there are no negative reaction force with the two lanes. But when the live load is single lane partial load, the reaction forces of 
inside supports on both abutment are negative (-1179 and -1135), it means that the two supports on both abutment are void in this case.

Table 4: The Calculation Results of Support Reaction under Overturning Test Basic Combination (KN)

\begin{tabular}{|c|c|c|}
\hline Support & $\begin{array}{c}\text { Two Lane Bias } \\
\text { Loading }\end{array}$ & $\begin{array}{c}\text { Single Lane Bias } \\
\text { Loading }\end{array}$ \\
\hline outside1 & 5865 & 5453 \\
\hline inside1 & 2645 & $\mathbf{- 1 7 6 0}$ \\
\hline 2 & 9964 & 7627 \\
\hline 3 & 10140 & 7797 \\
\hline 4 & 9877 & 7535 \\
\hline 5 & 9937 & 7592 \\
\hline 6 & 10137 & 7762 \\
\hline 7 & 10141 & 7767 \\
\hline 8 & 9925 & 7582 \\
\hline 9 & 9919 & 7574 \\
\hline 10 & 10151 & 7802 \\
\hline 11 & 9871 & 7537 \\
\hline outside12 & 5950 & 5536 \\
\hline inside12 & 2602 & $\mathbf{- 1 8 0 1}$ \\
\hline
\end{tabular}

The same result as above occurs when the partial factor of live load is 3.4 (overturning basic load combination): there are no negative reaction force with the two lanes, but when the live load is single lane partial load, the reaction forces of inside supports on both abutment are negative which is shows greater negative reactions forces $(-1760$ and 1801). The above results fully illustrate that the single lane bias load condition is harmful to the overturning resistance of the structure, and also reflects the risk of the abutment void.

\section{CHECKING CALCULATION OF BEARING CAPACITY OF SINGLE COLUMN PIER BEAM CONSOLIDATION}

According to the bearing cavity results, since the existence of the risk bearing separation bridge under eccentric loads, the bearing capacity of the single column pier against overturning play a decisive role, if the bearing capacity of pier is enough to resist overturning load, the anti overturning ability of the bridge will meet the requirements of the bridge pier, if the carrying capacity of the pier is insufficient, the anti overturning checking calculation must be carried out in the superstructure with considering extreme state that the pier has cracked.

Table 5: The Internal Forces of Top Section on Pier under Different Load Combinations

\begin{tabular}{|c|c|c|c|}
\hline Internal Force & $\begin{array}{c}\text { Short Term } \\
\text { Combination }\end{array}$ & $\begin{array}{c}\text { Basic } \\
\text { Combination }\end{array}$ & $\begin{array}{c}\text { Overturning Basic } \\
\text { Combination }\end{array}$ \\
\hline $\begin{array}{c}\text { Bending } \\
\text { Moment (kNm) }\end{array}$ & 1880 & 2271 & 7320 \\
\hline $\begin{array}{c}\text { Axial Force } \\
(\mathrm{kN})\end{array}$ & 3080 & 3560 & 3200 \\
\hline
\end{tabular}

Through reading the maximum transverse bending moment of two consolidation piers under single lane partial load in Midas Civil 2015, the corresponding load condition can be got by moving load and tracker. Then the synchronous axial force of the maximum bending moment can be obtained by applying load case above, so to determine the most unfavorable the internal force combination as shown in Table 4.

The carrying capacity and crack width of the structure are checked by "circular section eccentric compression and bending member checking" modular in bridge design software QLT 7.78, the result shown as in Table 5. According to the calculation results above, both the bearing capacity and the crack width of the consolidation pier meet the requirements of code, but when the load case is combination of overturning, they don't meet the requirements of code, so the bearing capacity of the consolidation pier is insufficient.

Table 6: The Results of Consolidation Pier Top Section Internal Force Checking Calculation in Ultimate Limit State of Bearing Capacity and Service Ability Limit State

\begin{tabular}{|c|c|c|c|c|}
\hline Combination & Classification & $\begin{array}{c}\text { Internal } \\
\text { Force }\end{array}$ & Resistance & $\begin{array}{c}\text { Whether } \\
\text { Satisfied }\end{array}$ \\
\hline $\begin{array}{c}\text { Short Term } \\
\text { Combination }\end{array}$ & $\begin{array}{c}\text { Bending } \\
\text { moment } \\
(\mathrm{kNm})\end{array}$ & 1880 & \multirow{2}{*}{$\begin{array}{c}\text { Crack } \\
\text { width } \\
0.097 \mathrm{~mm}\end{array}$} & Yes \\
\cline { 2 - 3 } & $\begin{array}{c}\text { Axial } \\
\text { force } \\
(\mathrm{kN})\end{array}$ & 3080 & 3480 & Yes \\
\hline \multirow{2}{\text{TheBasic}}{$\begin{array}{c}\text { Bending } \\
\text { moment } \\
\text { (kNm) }\end{array}$} & $\begin{array}{c}\text { Axial } \\
\text { force } \\
(\mathrm{kN})\end{array}$ & 3560 & 5456 & Yes \\
\cline { 2 - 3 } & $\begin{array}{c}\text { Bending } \\
\text { mement } \\
(\mathrm{kNm})\end{array}$ & 7320 & 2660 & No \\
\cline { 2 - 3 } $\begin{array}{c}\text { Axial } \\
\text { The Casic } \\
\text { Combination } \\
\text { With } \\
\text { Overturning }\end{array}$ & 3200 & 1163 & No \\
\hline
\end{tabular}

7. THE ANTIOVERTURNING CHECKING CALCULATION OF THE SMALL RADIUS CURVED CONTINUOUS GIRDER BRIDGE

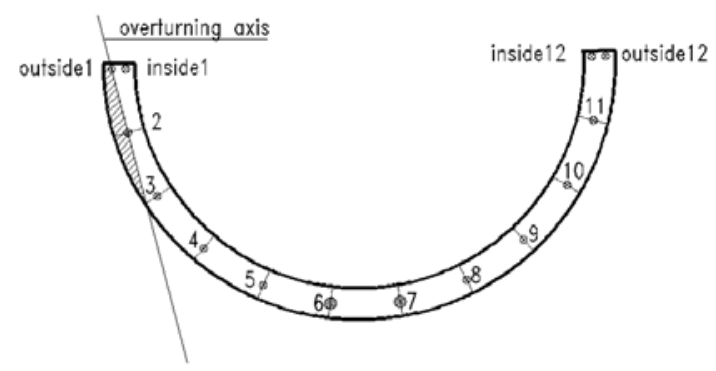

Figure 3: The first type of overturning axis

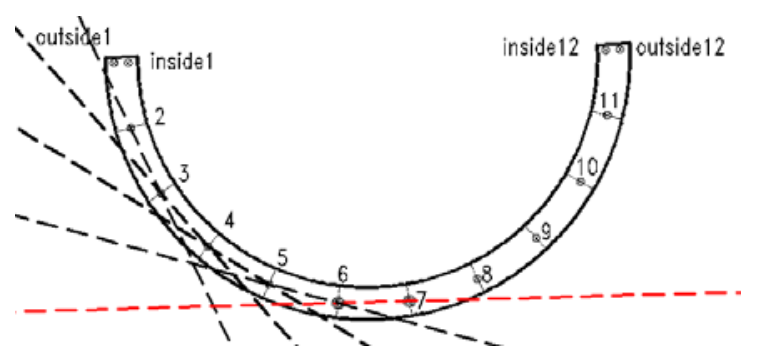

Figure 4: The second type of overturning axis

Since the carrying capacity of the consolidation pier is insufficient, the anti overturning checking calculation must be carried out in the superstructure with considering extreme state that the pier has cracked assuming that the consolidated pier is reducing to hinge support. Based on literature, there are two possible capsizing axe types for this bridge: one for the line of the abutment outside support and the secondary single pier support, as shown in figure 3 [2].

The other is the connection line of the two-center pier support, there are 5 cases as shown in figure 4 .

Table 7: The calculation process stability coefficients of the overturning axis 1 in Figure. 2

\begin{tabular}{|c|c|c|c|}
\hline Support & $R_{G i}$ & $x_{i}$ & $R_{G i} x_{i}$ \\
\hline outside 1 & 573 & 0 & 0 \\
\hline inside 1 & 974 & 4.3 & 4188.2 \\
\hline 2 & 2980 & 0 & 0 \\
\hline 3 & 3407 & 4.0 & 13628 \\
\hline 4 & 3048 & 14.0 & 42672 \\
\hline 5 & 3135 & 29.3 & 91855.5 \\
\hline 6 & 3419 & 48.4 & 165479.6 \\
\hline 7 & 3421 & 69.9 & 239127.9 \\
\hline 8 & 3120 & 91.8 & 286416 \\
\hline 9 & 3084 & 112.5 & 346950 \\
\hline 10 & 3419 & 130.0 & 444470 \\
\hline 11 & 2894 & 143.1 & 414131.4 \\
\hline
\end{tabular}




\begin{tabular}{|c|c|c|c|}
\hline outside 12 & 666 & 147.6 & 98301.6 \\
\hline inside 12 & 931 & 151.9 & 141418.9 \\
\hline \multicolumn{3}{|c|}{$\sum R_{G i} X_{i}$} & 2288639.1 \\
\hline$P_{k}$ & 186 & $q_{k}$ & 7.88 \\
\hline$\Omega$ & 162.7 & $e$ & 4.6 \\
\hline \multicolumn{3}{|c|}{$(1+\mu)\left(q_{k} \Omega+P_{k}\right) e$} & 8468 \\
\hline \multicolumn{3}{|c|}{$\gamma_{\text {af }}$} & 270.3 \\
\hline
\end{tabular}

The stability factor corresponding to the above anti overturning axis can be worked out based on the checking formula of overturning resistance literature as shown in the following: [2].

$$
\gamma_{q f}=\frac{\sum R_{G i} x_{i}}{(1+\mu)\left(q_{k} \Omega+P_{k}\right) e}
$$

\section{$\gamma_{\text {qf }}-$ anti-overturning stability factor;}

$R_{G i} \longrightarrow$ the reaction force of each support in the condition of completed bridge ( $\mathrm{kN}$, as shown in table 1 );

$X-$ the vertical distance of each support to the axis of overturning $\stackrel{i}{(\mathrm{~m})}$;

$\mu_{k}$ - -impact coefficient (automatically considered in Midas Civil 2015);

$q$ - - uniform load in lane load $(\mathrm{kN} / \mathrm{m})$

$P_{k}$ - concentrated load in lane load $(\mathrm{kN})$;

$\mathrm{e}$ - - the vertical distance of the lateral least favorable lane position to the capsizing axis $(\mathrm{m})$;

$\Omega$ - the area between the overturning axis and the transverse loading Lane (m2);

Will input the data in Table 1 and related parameters together into the formula (1), we can calculate the stability coefficient of the bridge, the overturning axis of the limited space. Limited to the length of this article, we only take the overturning axis 1 for example, to illustrate the calculation process of the stability factor against overturning as shown in Table 8. The stability coefficients corresponding to other kinds of capsizing axes are shown in Table 9.

Table 8: The results of stability coefficient of each capsizing axis

\begin{tabular}{|c|c|}
\hline Overturning Axis Number & Stability Coefficient \\
\hline 1 & 270.3 \\
\hline 2 & 153.0 \\
\hline 3 & 120.7 \\
\hline 4 & 95.6 \\
\hline 5 & 79.6 \\
\hline 6 & 74.1 \\
\hline
\end{tabular}

According to the data in Table 9, the stability coefficients of the 6 types of capsizing axes are great, far exceeding the lower limit of the overturning stability factor 2.5. Among that the stable coefficient of the first type of axis is biggest, and the other 5 are smaller. It's mainly because that the stable coefficients of the bridge is related to vertical distance of each support to the axis of overturning direction as shown in formula (1).

In summary, the results of the stability coefficient with all kinds of overturning axis in multi span continuous curved box girder show that the anti overturning performance is very strong because of the more support means the more effective constraints on the structure, especially when the radius is small. But because multi span continuous beam is indeterminate structure, coupled with the impact of fixed pier, the force is very complex, the following factor must be considered to determine the best length of the continuous structure: the displacement of the support and the change of temperature, shrinkage and creep of concrete, etc.

Furthermore, the results of this paper show that, with the existence of fixed pier of continuous curved box girder, the bearing capacity of the pier is more important, which must be completely considered in design of the similar structure.

\section{CONCLUSIONS AND RECOMMENDATIONS}

Through the finite element analysis and anti overturning checking of multi span reinforced concrete curved continuous box girder with single column consolidation pier, the following conclusions and suggestions are as the following:

1. The bridge studied in this paper has the risk of bearing voids under the combined action of the ultimate load capacity, so it can't meet the requirement of checking the void of the support in the relevant codes! Recommended strongly that the maintenance department consider setting tensile bearing beam in abutment, to ensure the durability of the bridge bearing; In addition, regular support inspection must be strengthening, once disease in support is found, the related maintain measure must to be carried out immediately by consulting relevant technology, management and other departments.

2. Since the existence of fixed pier of continuous curved box girder, the bearing capacity of the pier is more important, this must be completely considered in the design of the similar structures.

3. the results of the stability coefficient with all kinds of overturning axis in multi span continuous curved box girder show that the anti overturning performance is very strong because of the more support means the more effective constraints on the structure, especially when the radius is small.

\section{REFERENCES}

[1] CCP. 2004. Code for design of highway reinforced concrete and prestressed concrete bridges and culverts. (JTG D62-2004) [S]. Beijing: China Communications Press.

[2] CCP. 2012. Code for design of highway reinforced concrete and prestressed concrete bridges and culverts. (Draft, JTG D62-2012) [S]. Beijing: China Communications Press.

[3] Guidelines for the evaluation and checking computations of lateral overturning resistance of single column pier bridges. [S]. China Communications highway planning and Design Institute Co Ltd, Guangdong communications planning and Design Institute Limited by Share Ltd. 2015.

[4] GTGC. 2015. Guidelines for the evaluation and checking computations of lateral overturning resistance of single column pier bridges (supplementary). [S]. Guangdong Traffic Group Co., Ltd.

[5] CCP. 2014. Highway engineering technical standard (JTG B01-2014). [S]. Beijing: China Communications Press.

[6] CCP. 2015. General code for design of highway bridges and culverts (JTG D60-2015). [S]. Beijing: China Communications Press.

[7] Yong, W., Yongjian, L., Fang, T.X. 2006. Study on simplified algorithm of partial load factor of concrete continuous box girder. [J]. Journal of Changsha Traffic College, (9). 